\title{
Löfgren Syndrome Developing during Infliximab Therapy for Crohn's Disease: A Case Report
}

\author{
Isabel Coman MD, J. Manuel Dominguez MD, Annie Belisle MD
}

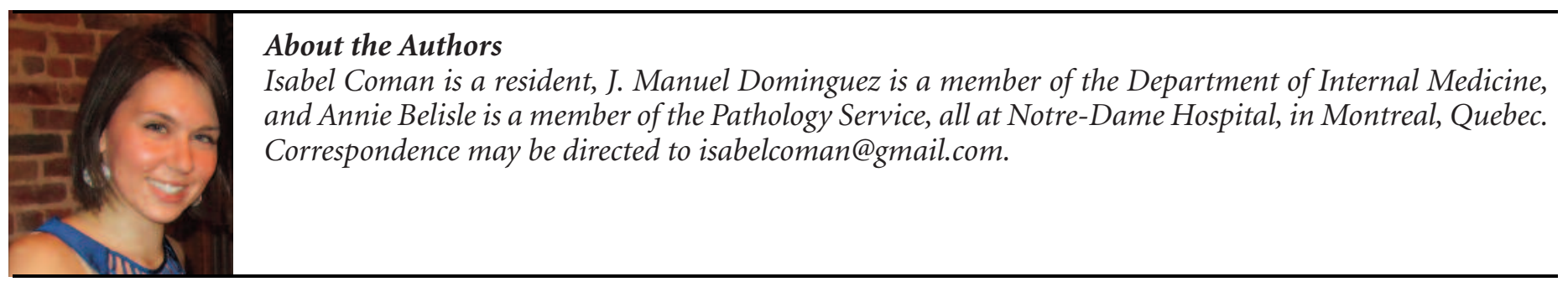

\section{Summary}

Tumour necrosis factor alpha (TNF $\alpha)$ antagonists are biological response modifiers increasingly used to effectively treat a wide array of inflammatory diseases such as Crohn's disease and rheumatoid arthritis. Anti-TNF $\alpha$ agents are also used in the treatment of steroidrefractory granulomatous diseases, with reported success. Paradoxically, an increasing number of cases of anti-TNF-induced sarcoidosis are being reported. The acute form of sarcoidosis, Löfgren syndrome, is characterized by mediastinal adenopathy, erythema nodosum, arthralgia, and fever. This article describes the case of a patient with Crohn's disease who developed Löfgren syndrome during treatment with infliximab. To our knowledge, this is the first case of Löfgren syndrome developing during treatment with a TNF $\alpha$ antagonist.

\section{Résumé}

Les antagonistes du facteur de nécrose tumorale alpha (TNF $\alpha$ ) sont des modificateurs de la réponse biologique de plus en plus employés pour traiter efficacement toute une gamme de maladies inflammatoires, dont la maladie de Crohn et la polyarthrite rhumatoïde. Les antiTNF $\alpha$ sont aussi utilisés avec succès dans le traitement des maladies granulomateuses réfractaires aux stéroïdes. Paradoxalement, on signale un nombre croissant de cas de sarcoïdose induite par les anti-TNF. La forme aiguë de la sarcoïdose, le syndrome de Löfgren, se caractérise par une adénopathie médiastinale, des érythèmes noueux, de l'arthralgie et de la fièvre. Nous décrivons ici le cas d'une patiente atteinte de la maladie de Crohn qui a développé le syndrome de Löfgren pendant un traitement à l'infliximab. À notre connaissance, il s'agit du premier cas de syndrome de Löfgren à survenir pendant l'administration d'un antagoniste du TNF $\alpha$.

\section{Clinical Notes}

A 56-year-old woman presented to the emergency room after two weeks of experiencing progressive dyspnea and a dry cough. She had a 35-year history of Crohn's disease and had had a colectomy at 28 years of age. She had suffered recurrent episodes of pouchitis, which, due to infliximab, was in clinical remission. Two months after starting treatment, she developed painful subcutaneous nodules on the lower limbs and around the elbows, arthralgia in the knees, increasing fatigue, and occasional fever. Her gastroenterologist discontinued anti-TNF treatment and referred her for a skin biopsy; this showed granulomatous inflammatory infiltrates in the deep subcutaneous fat, with giant cells, histiocytes, and few lymphocytes (Figure 1) Necrosis was not present. The differential diagnosis included atypical erythema nodosum, atypical sarcoidosis, and cutaneous Crohn's disease.

Blood tests revealed a sedimentation rate of $30 \mathrm{~mm} / \mathrm{h}$, a Creactive protein level of $20 \mathrm{mg} / \mathrm{L}$, an elevated angiotensin-converting enzyme (ACE) level of $134 \mathrm{U} / \mathrm{L}$ $(N<8-52)$, and positive antinuclear antibodies, with antideoxyribonucleic acid antibodies of $33 \mathrm{U} / \mathrm{mL}(N<30)$. In the extractable nuclear antigen (ENA) profile, the centromere $\mathrm{B}$ 


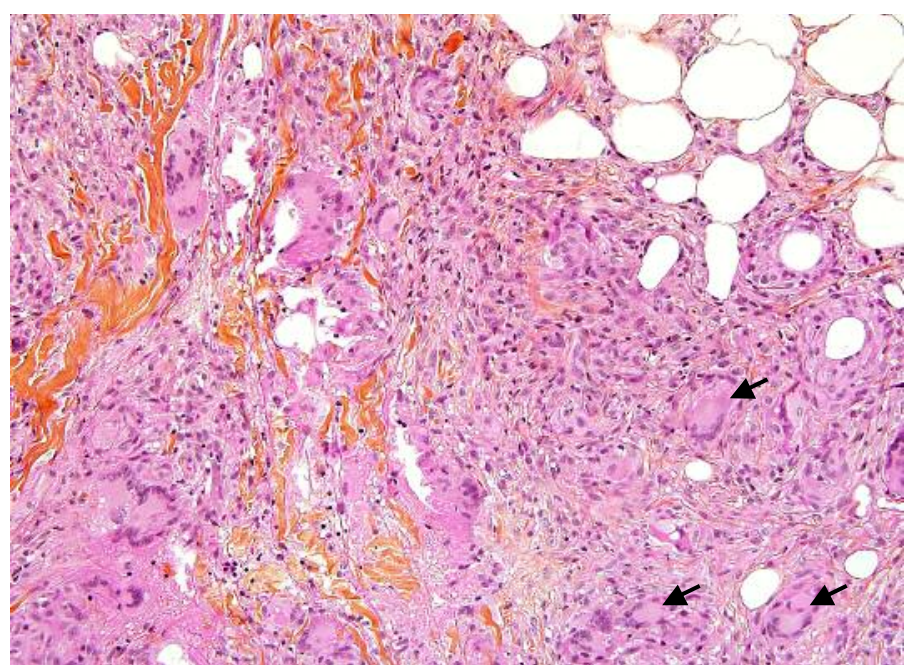

Figure 1. Granulomatous panniculitis with multinucleated giant cells (arrows) and epithelioid histiocytes in the subcutaneous fat (hematoxylin phloxine saffron, original magnification $\times 400$ ). protein was positive at 5.70 without any signs or symptoms of scleroderma. Complete blood count, renal function, electrolytes, and morning cortisol level were normal. The test result for antineutrophil cytoplasmic autoantibody (ANCA) was negative; the anti-Saccharomyces cerevisiae antibody (ASCA) and immunodeficiency profile was negative; and serological markers for tuberculosis, Epstein-Barr virus, hepatitis B and C, toxoplasmosis, syphilis, and human immunodeficiency virus were negative.

Computed tomography angiography of the lungs showed bilateral hilar and mediastinal adenopathy, numerous micronodules in the pulmonary parenchyma, and peribronchial thickening. Pulmonary embolism was excluded.

Pulmonary function tests showed a reduced diffusion capacity of carbon monoxide (DLCO) level ( $72 \%$ of the expected level), with preserved lung volumes and no obstruction. The patient's echocardiogram was normal; her systolic pulmonary
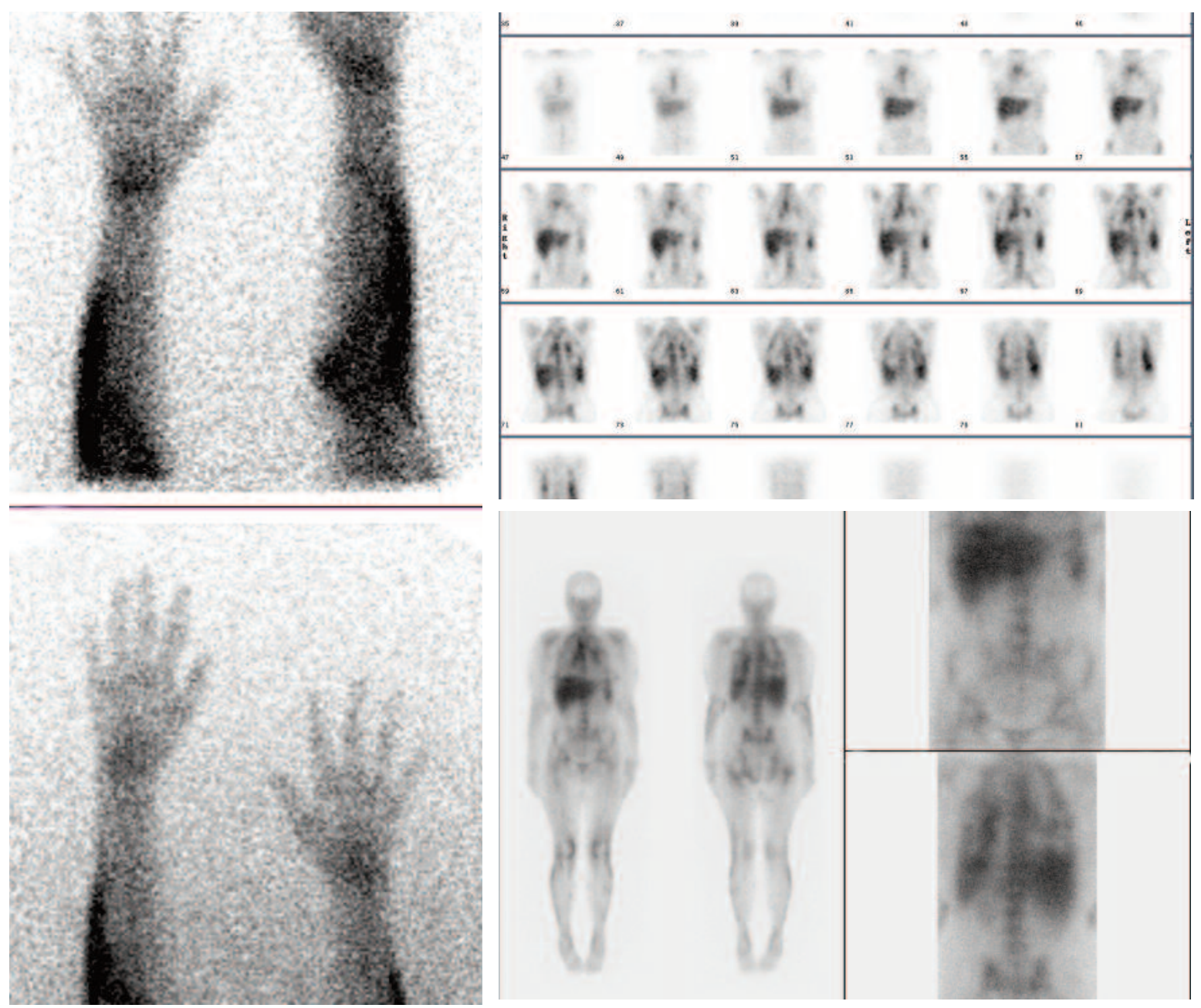

Figure 2. Bone scintigraphy patterns evoking acute sarcoidosis-associated Löfgren syndrome, with intense radiotracer uptake in the mediastinum and hila and significant uptake in the soft tissues in the external side of the elbows to the distal third of both forearms, corresponding to the described subcutaneous nodules. Uptake of superficial soft tissues on the lateral side of the lower limbs and focal round uptake on the medial side of the lower right leg are present, also in relation with subcutaneous nodules. 
artery pressure was $30 \mathrm{~mm} \mathrm{Hg}$. Bronchoscopy was normal. Bronchoalveolar lavage (BAL) fluid was sterile and contained $98 \%$ macrophages and $2 \%$ lymphocytes.

A bone scan showed a typical tracer pattern, with intense radiotracer uptake in the hilum and mediastinum and in posterior lung fields. There was also significant uptake in the soft tissue of both elbows and forearms (medially) and in that of the lower limbs (laterally), corresponding to the described subcutaneous nodules.

These subcutaneous skin nodules gradually resolved during her hospital stay, some seven weeks after her last dose of infliximab. Corticosteroid was not required, and she was discharged with close follow-up by her gastroenterologist. One month after discontinuation of infliximab, she was started on prednisone because of a flare-up of Crohn's disease.

\section{Discussion and Literature Review}

Anti-TNF drugs are monoclonal antibodies that reduce the inflammatory response by interfering with the body's production of TNF cytokines. These pharmaceutical molecules have dramatically changed the management of inflammatory diseases and are considered an efficient treatment option for rheumatoid arthritis, spondylarthritis, psoriasis, Crohn disease, and ulcerative colitis.

Sarcoidosis is a granulomatous disease that can affect all organs. Although the etiology of sarcoidosis is still unknown, it is the interaction between CD4 $\mathrm{T}$ cells and specific antigenpresenting cells that results in the inflammation process and the formation of granulomas. The molecular mechanisms implicated in this process include the production of cytokines that activate lymphocytes and macrophages, with subsequent TNF production. This leads to the amplification of the inflammatory response and causes the formation of noncaseating epithelioid cell granulomas. Although the firstintention treatment of sarcoidosis remains prednisone, the use of the anti-TNF agent infliximab for treating prednisoneresistant sarcoidosis has had some reported success in a few small studies. $^{1}$

Thus, reports of patients developing sarcoid-like reactions during anti-TNF therapy are paradoxical and not yet understood. Most evidence of these adverse reactions comes from case reports. To date, 48 cases of anti-TNF-induced sarcoidosis have been reported; most were encountered in patients with inflammatory arthropathies (46/48) who were taking etanercept (28/48) or, less frequently, infliximab (14/48) or adalimumab (6/48). Molecular differences between these agents partly explain why more cases of sarcoidosis develop with etanercept than with the other two agents. Infliximab and adalimumab are TNF antibodies that suppress TNF better than etanercept does. Hence, the structural, pharmacokinetic, and pharmacodynamic differences between anti-TNF drugs correlate well with reports of more remissions of sarcoidosis when infliximab and adalimumab are used than when etanercept is used. Some studies even found a worsening of sarcoidosis during treatment with etanercept. ${ }^{2}$ In 2009, a well-designed French study with data taken from reports from members of a rheumatological association estimated the incidence of this reaction to be 1 in $2,800 .{ }^{3}$ One literature review (21 patients) noted that $85 \%$ of radiological patterns were stages I and II and that ACE values were high in $53 \%$ of patients. The same study noted that antiTNF treatment was discontinued in all patients but that only $52 \%$ of patients were started on steroids. ${ }^{4}$

For all patients who developed sarcoid-like reactions after starting an anti-TNF drug regimen, the discontinuation of the drug (with or without the use of corticosteroids) has led to improvement. When the causal agent was restarted, recurrence was observed. However, when a different anti-TNF agent was introduced, the outcome varied: some patients relapsed, and some did not.

To the best of our knowledge, this is the second case of infliximab-induced sarcoidosis in a patient with Crohn's disease. More important, it is the first case of Löfgren syndrome developing during treatment with an anti-TNF drug.

\section{References}

1. Daïen CI, Monnier A, Claudepierre P, et al. Sarcoid-like granulomatosis in patients treated with tumor necrosis factor blockers: 10 cases. Rheumatology (Oxford, England) 2009;48(8):883-6.

2. Gifre L, Ruiz-Esquide V, Xaubet A, et al. Lung sarcoidosis induced by TNF antagonists in rheumatoid arthritis: a case presentation and literature review. Arch Bronconeumol 2011;47(4):208-12.

3. Skoie IM, Wildhagen K, Omdal R. Development of sarcoidosis following etanercept treatment: a report of three cases. Rheumatol Int 2012;32(4):1049-53.

4. Burns AM, Green PJ, Pasternak S. Etanercept-induced cutaneous and pulmonary sarcoid-like granulomas resolving with adalimumab. J Cutan Pathol 2012;39(2):289-93.

5. Kanellopoulou T, Filiotou A, Kranidioti H, et al. Sarcoid-like granulomatosis in patients treated with anti-TNF factors. A case report and review of the literature. Clin Rheumatol 2011:30(4):581-3.

6. Tong D, Manolios N, Howe G, et al. New onset sarcoid-like granulomatosis developing during anti-TNF therapy: an under-recognized complication. Intern Med J 2012;42(1):89-94.

7. O’Regan A, Berman JS. In the clinic: sarcoidosis. Ann Intern Med 2012;156(9):ITC5-1. 